\title{
PULMONARY HAEMOSIDEROSIS WITH SEVERE RENAL LESIONS (GOODPASTURE'S SYNDROME)
}

\author{
BY \\ J. G. CRUICKSHANK AND R. A. PARKER \\ From the Department of Pathology, University of Cambridge
}

(RECEIVED FOR PUBLICATION SEPTEMBER 19, 1960)

Two main varieties of endogenous pulmonary haemosiderosis have been described. One type is associated with chronic cardiac failure due usually to mitral stenosis (Lendrum, Scott, and Park, 1950) ; and the other, not associated with chronic cardiac failure, is most often seen in children (Ceelen, 1931), although it may also occur in young adults (Hamer, 1955). Renal lesions in these cases are uncommon and were found in only five out of the 69 recorded cases (Heptinstall and Salmon, 1959).

A third variety of the disease occurs in young and middle-aged adults and is characterized by the presence of severe renal lesions with or without chronic heart failure. The first case of this sort was described by Goodpasture in 1919. Stanton and Tange (1958) presented a series and suggested that the condition should be referred to as "Goodpasture's syndrome" at least until the aetiology becomes less obscure.

The diagnosis is frequently made only at necropsy, and it is therefore felt justified in recording four further cases in an attempt to define the clinical and pathological pattern of the disease.

\section{Case Reports}

CASE 1.-A 17-year-old hotel maid was first seen in January, 1957, at another hospital with a history of coughing up blood for two months. No abnormality was found in the chest on clinical or radiological examination. Bronchoscopy and bronchography were negative. Haemoglobin was $59 \%$ and the white blood count was 7,000 per c.mm. with $1 \%$ eosinophils. The Mantoux test was positive at 1 in 100 and negative at 1 in 1,000. She was discharged to convalescence in April, the causes of the haemoptysis remaining a mystery.

Two weeks later she was readmitted with lassitude and breathlessness. She was transfused with 2 pints of blood and given a course of " tablets" for three weeks. Towards the end of May she was able to return to work.

She remained well until six weeks before her final admission, when her ankles began to swell and she became short of breath. One week before admission she began coughing up small quantities of bright red blood and the dyspnoea increased. On the day of admission she suddenly experienced severe pain in the left loin radiating to the left lower chest. The chest pain was pleuritic in type.

There were no urinary or alimentary symptoms. Early in 1956 she had had "blackouts" associated with menorrhagia successfully treated by curettage. One sister is a deaf-mute epileptic.

Examination on admission showed a dyspnoeic, illlooking girl with gross pallor of the mucous membranes. There was bilateral pitting oedema of the ankles. Jugular venous pressure was not raised. The pulse rate was 120 per minute and blood pressure $125 / 80 \mathrm{~mm}$. Hg. Heart sounds were normal. There was diminished movement, dullness, and diminished vocal resonance at the left base. Fine crepitations were heard at the left apex and left base. Palpation of the abdomen revealed exquisite tenderness in the left loin and left renal angle. The liver and spleen were not felt and there was no lymphadenopathy. The central nervous system was normal. No petechial haemorrhages were seen on the skin. Hess's test was negative.

The haemoglobin was $5.5 \mathrm{~g}$. per $100 \mathrm{ml}$. and the haematocrit $17 \%$. The red count was $1,900,000$ per c.mm., M.C.H. 29 , M.C.V. 89.5 c $\mu$, M.C.H.C. $32.3 \%$ Reticulocytes were $2.1 \%$. The white count was 12,475 (85\% neutrophils, $10 \%$ lymphocytes, $5 \%$ monocytes) Platelets were 500,000 per c.mm. The E.S.R. was 78 $\mathrm{mm}$. in one hour. The blood urea was $54 \mathrm{mg}$. per $100 \mathrm{ml}$ and total protein $5.2 \mathrm{~g}$. per $100 \mathrm{ml}$. The urine was acid and contained protein +++ but no sugar. $\operatorname{Red}$ cells were numerous and occasional pus and epithelial cells were present. Some hyaline and granular casts were seen. Culture showed a faecal streptococcus. Electrophoresis showed a normal globulin pattern and a gross deficiency of the albumin fraction. A chest radiograph showed bilateral lower lobe consolidation.

She was transfused with 3 pints of blood, and streptomycin, $1 \mathrm{~g}$. per day, was begun to control the urinary infection. During the day she had several small haemoptyses and vomited some chocolatecoloured material two or three times. Deterioration was rapid, and by the following morning her pulse rate had risen to 160 , though the blood pressure remained 
at $130 / 70 \mathrm{~mm}$. $\mathrm{Hg}$. She passed rapidly into coma and died the day after admission.

\section{POST-MORTEM FINDINGS (P57/249)}

The left pleural cavity contained $200 \mathrm{ml}$. of straw-coloured fluid. Both lungs were heavy and oedematous. The cut surface was a dark red-brown colour and was in places frankly haemorrhagic. This appearance extended out from the hilar regions in a "batswing" fashion. Towards the periphery the lesions became more focal and appeared as raised red-grey dots. The Prussian blue test to these areas was strongly positive. Blood-stained fluid was present in all the branches of the main bronchi.

The kidneys were enlarged and tense. Numerous petechial haemorrhages were scattered over the surfaces. The cortices bulged on cut surfaces and the cortico-medullary demarcations were blurred. The lower urinary tract was normal.

The heart was normal and no other significant abnormality was found in any other organ.

Microscopy.-All the sections from the hilar regions of the lungs had much the same appearance. There was extensive intra-alveolar haemorrhage admixed with oedema fluid and fibrin. Widespread haemosiderin deposition was seen (Fig. 1) made up of

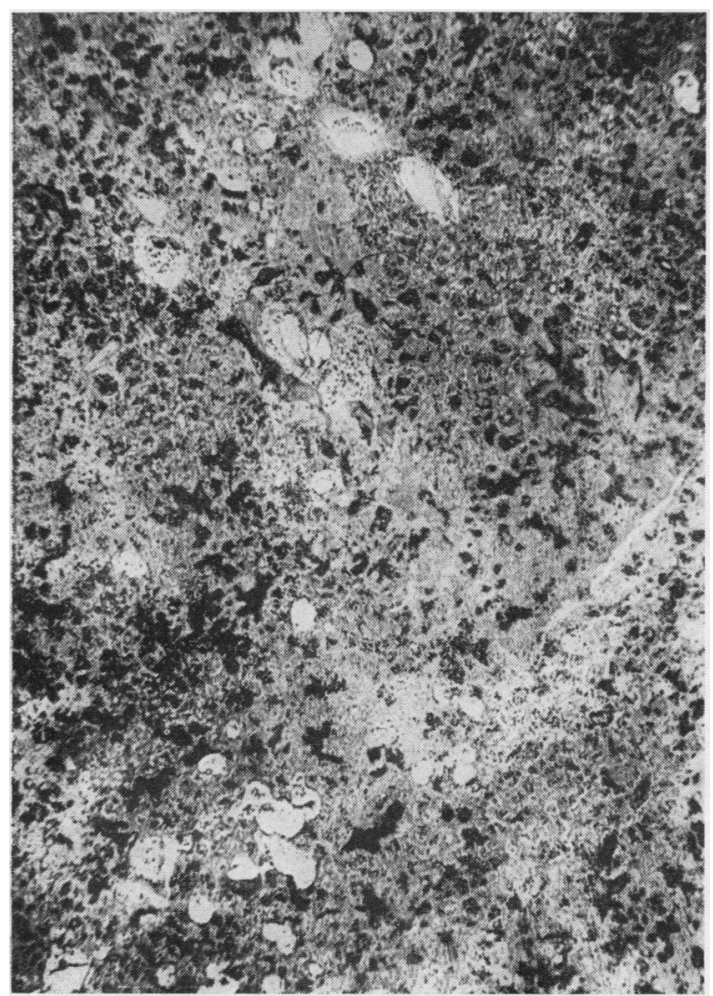

FIG. 1.-Case 1: widespread haemosiderin and pulmonary oedema (Perls' stain, $\times 17$ ).

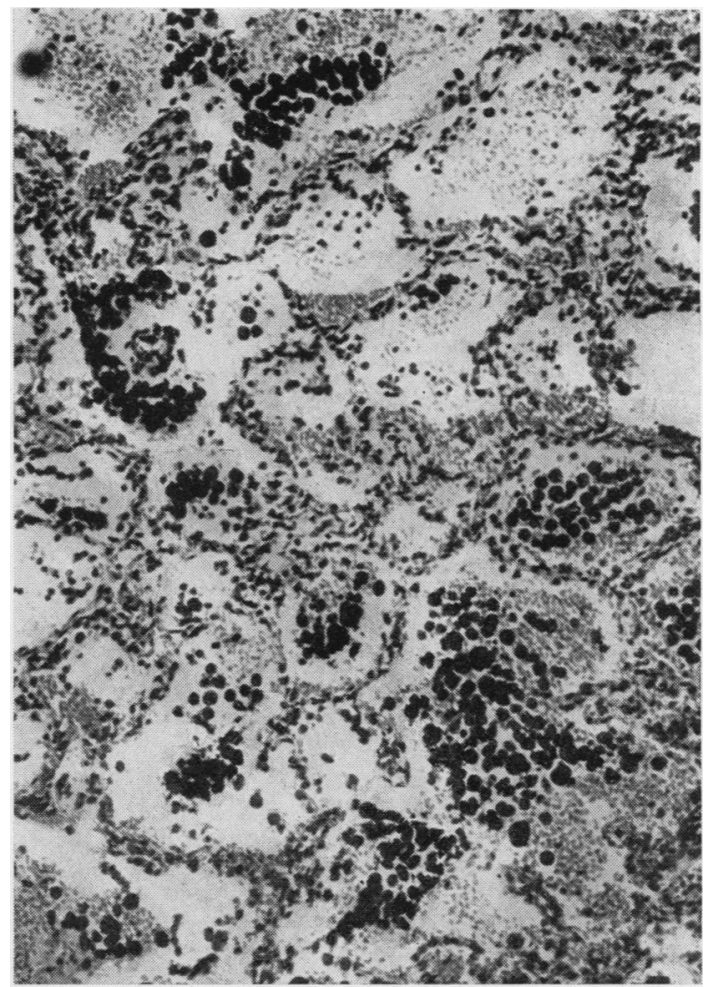

FIG. 2.-Case 1: intra-alveolar haemorrhage and focal aggregates of haemosiderin-containing macrophages (Perls' stain, $\times 100$ ).

focal collections in macrophages (Fig. 2). Very few polymorphonuclear leucocytes were seen. The alveolar walls were intact and there was no abnormality in the pulmonary arteries. The bronchial walls were normal, but there was blood-stained fluid in their lumina. Near the periphery the lesions were more discrete and were centred on terminal bronchioles. There was intraalveolar haemorrhage, oedema, and haemosiderosis in the neighbouring alveoli. Early organization was conspicuous.

The renal glomeruli were nearly all abnormal and there was considerable variety in the lesions seen due to there being different stages of the same lesion. Many lobules contained amorphous, pink-staining material resembling areas of fibrinoid necrosis (Fig. 3). There was very little endothelial proliferation, but slight polymorphonuclear infiltration was present. Epithelial crescent formation was frequent. All stages in glomerulo-fibrosis were seen from fine hyalinization to replacement by dense collagen bundles. Occasional glomeruli were converted into granulomatous masses in which some giant cells were seen. Capsular spaces were largely obliterated, but where present contained red blood corpuscles. Many tubules were dilated and contained protein in their lumina.

The arteries examined in over 20 sections of the lungs and kidneys were normal. 


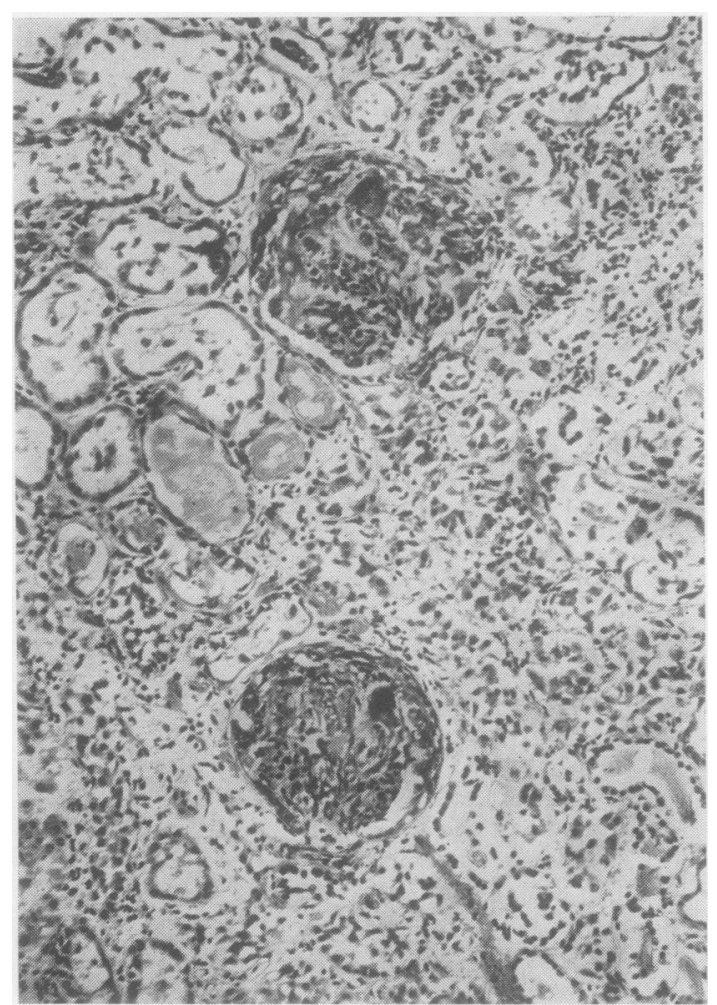

FIG. 3.-Case 1: glomeruli with crescent formation and fibrinoid in individual lobules (haematoxylin and eosin, $\times 110$ ).

CASE 2.-A 48-year-old housewife was admitted to hospital on August 26, 1958, with increasing breathlessness and exhaustion for three weeks.

She had not been well since 1942 when she had bad a severe attack of bronchitis. Since then she had had about 12 attacks of asthma a year until two years before, when the attacks ceased, though there was some residual dyspnoea on exertion. In May, 1958, the breathlessness returned gradually and in the past three weeks had been present at rest. She noticed she became blue on the slightest exertion, though her extremities were always warm. Ankle oedema had been present for 12 months.

She had no cough, no haemoptysis, and no chest pain. Her weight was steady and there were no symptoms referable to the urogenital or alimentary systems. There was no relevant past medical history. One of her three sisters was asthmatic.

On examination she was dyspnoeic and cyanosed. There was no clubbing. The pulse was 12 per minute and the blood pressure $105 / 60 \mathrm{~mm}$. $\mathrm{Hg}$. The jugular venous pressure was raised to $3 \mathrm{~cm}$. above the sternal notch; the legs were oedematous to the thighs and she had a sacral pad of oedema. The apex beat was 5 in. from the midline in the sixth interspace. There was a diastolic murmur to the left of the sternum maximal at the third interspace. The trachea was $\frac{\vec{P}}{\square}$ central; there was dullness to percussion and decreased air entry with fine crepitations at both $\frac{\bar{\sigma}}{\overline{0}}$ bases. Apart from hepatomegaly, there was no other $\frac{\bar{c}}{\vec{D}}$ abnormality in the abdomen. The central nervous $\stackrel{\mathbb{Q}}{\varrho}$ system was normal.

The haemoglobin was $17.5 \mathrm{~g}$. per $100 \mathrm{ml}$. and the haematocrit $62 \%$. There were 6,000 white cells per $\vec{\circ}$ c.mm. with a normal differential count. The urine $\vec{\overrightarrow{ }}$ contained protein ++ , a few epithelial cells, pus cells, $\vec{\omega}$ and red cells. Coliform bacilli were grown from the sediment. The blood urea was $46 \mathrm{mg}$. per $100 \mathrm{ml}$. $\vec{x}$ Plasma sodium was $133 \mathrm{mEq}$. per litre, potassium $\vec{\sigma}$ $4.3 \mathrm{mEq}$. per litre, chlorides $90 \mathrm{mEq}$. per litre, and $\rightarrow$ the $\mathrm{CO}_{2}$-combining power $32.5 \mathrm{mEq}$. per litre. Electrocardiograms showed right ventricular hyper- $\mathrm{N}$ trophy. A chest radiograph demonstrated increased

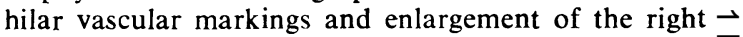
ventricular conus. A diagnosis of cor pulmonale was $\underset{\Omega}{\mathbf{a}}$ made and she was treated with digitalis, diuretics, oxygen, and aminophylline. After a slow start she $\frac{\supset}{\supset}$ responded well and was finally discharged on $\vec{\theta}$ October 5. She remained well for a month.

On the morning of November 6 she woke with pain, coldness, and numbness below both knees. During the morning the right leg recovered and the left leg became painless but remained rather numb and cold. There was no increase in the dyspnoea.

On examination she was cyanosed as before. The $\stackrel{\mathbb{D}}{\circ}$ pulse rate was 120 per minute and the blood pressure $\overrightarrow{\vec{T}}$ $100 / 70 \mathrm{~mm}$. Hg. There were signs of cardiac failure $\frac{0}{3}$ as before and of arterial occlusion in the left leg.

A diagnosis of saddle embolus which had moved and impacted in the left popliteal artery was made. and anticoagulant therapy instituted. By the next day both legs were the same on examination and the left femoral pulse became palpable.

The blood count and haemoglobin were normal. $\frac{\sigma}{3}$ The urine contained large quantities of protein and a few red cells. The blood urea and plasma electrolytes $\delta$ were normal. The chest radiograph was essentially unchanged.

Four days after admission she developed auricular flutter. Despite treatment she went into deeper cardiac $\frac{7}{0}$ failure, developed signs of cerebral anoxia, and died on January 28, 1959.

\section{PoST-MORTEM Findings (P59/071)}

A fairly well-defined, firm, red lesion was present in the right lung in the costophrenic angle. It was wedge-shaped but rather poorly defined. The lungs $\frac{\bar{D}}{\Phi}$ were elsewhere bulky, heavy, and oedematous. The whole parenchyma was firmer than usual and a dark brown colour. Towards the periphery a more normal $\frac{T}{0}$ pattern supervened, but there were no focal lesions $\frac{\vec{D}}{\Phi}$ macroscopically. There was hyperaemia of the bronchi, which contained only a small amount of $\stackrel{\mathbb{Q}}{\Omega}$ mucus. The pleurae were normal and contained no $\sigma$ excess of fluid. The hilar lymph nodes were enlarged and fleshy. 


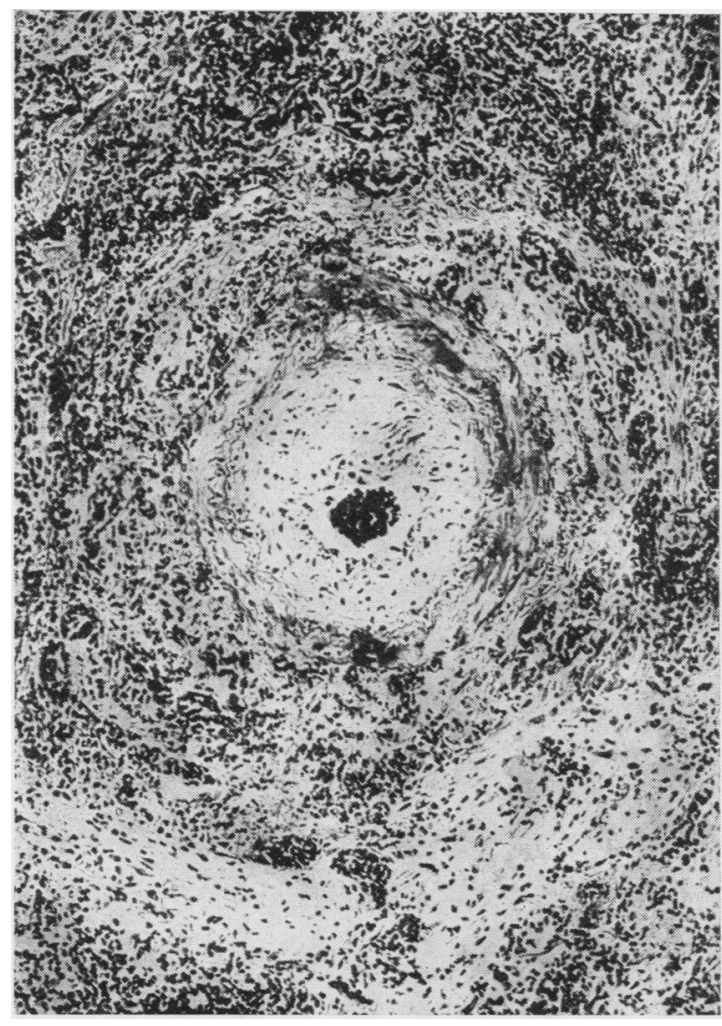

FIG. 4.-Case 2: pulmonary artery with gross cellular infiltration in its wall (haematoxylin and eosin, $\times 100$ ).

The kidneys weighed 165 and $215 \mathrm{~g}$. and the capsules stripped easily. The surfaces were congested and were diffusely mottled with rather irregular minute yellow dots which lay flush with the surface. This speckled appearance was visible on the cut surface scattered throughout the cortex, but was not present in the medulla. The glomeruli could be seen as translucent pale dots. There was adequate cortico-medullary demarcation and the medulla was normal. The lower urinary tract was normal.

There was hypertrophy of the right ventricle (1.5 cm. thick) (heart weight 345 g.). The right atrium was dilated and the foramen ovale had a gap $1 \mathrm{~cm}$. in diameter at its inferior border. The right auricular appendage contained an ante-mortem thrombus fairly firmly adherent to its walls. An organizing thrombus was present in the left popliteal artery. There was fairly recent thrombus in the calf veins of the left leg.

The liver was enlarged and there was gross central congestion. No significant abnormality was found in any other organ.

Microscopy.-Discrete and diffuse lesions were fairly evenly distributed throughout both lungs. The former consisted of small areas of intra-alveolar haemorrhage usually around a bronchiole. Some organization was present and many haemosiderin- laden macrophages were scattered throughout the lesion. The more diffuse lesions consisted of widespread organizing intra-alveolar haemorrhage and haemosiderosis. In the centre of many of the more recently involved areas were damaged small arteries. Their walls and surrounding tissue were diffusely infiltrated by cellular material consisting of polymorphonuclear leucocytes and lymphocytes (Fig. 4). The intima of many were swollen and areas of eosinophilic amorphous material resembling fibrinoid were present (Fig. 5) in the walls for part or the whole of their circumference.

The glomeruli showed some cellular proliferation and swelling with moderate leucocytic infiltration. In many tufts the capillary walls were undergoing hyalinization. A little epithelial crescent formation was present. In contrast to Case 1 no fibrinoid material was seen in the glomeruli and only a few tufts showed advanced fibrosis. Occasional tubules were dilated and contained red and white cells.

Careful examination of the arteries in several sections of the kidneys and in representative sections of other organs revealed no abnormality.

CASE 3.-A 57-year-old butcher was admitted on September 30, 1956, complaining of coughing and retching for one day. For the previous four days he

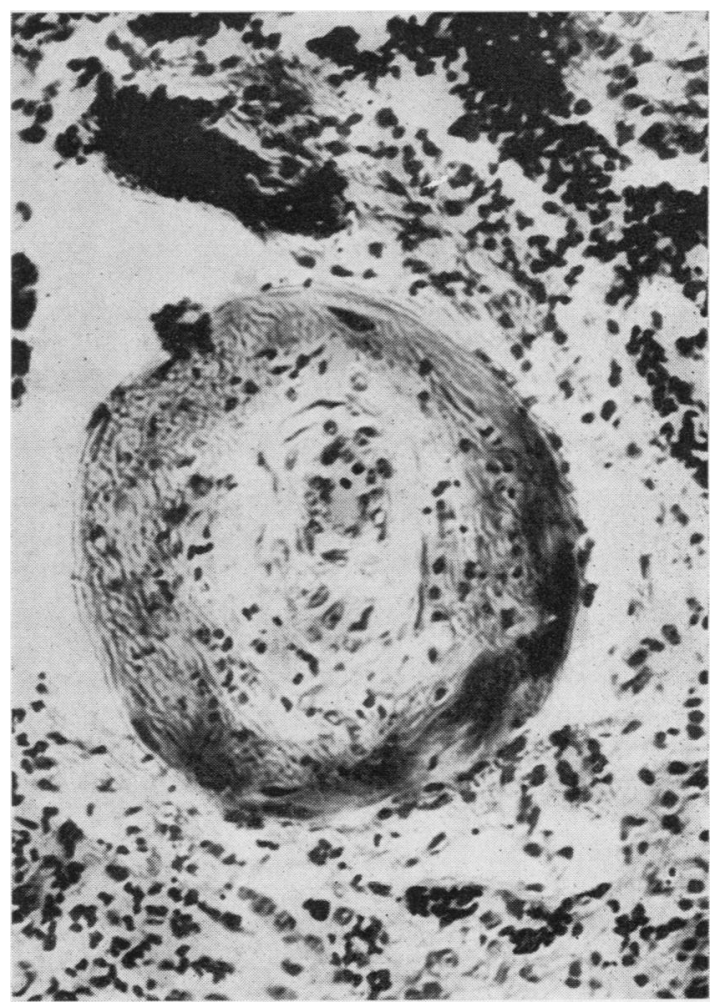

FIG. 5.-Case 2: pulmonary artery showing fibrincid material within its wall (haematoxylin and eosin, $\times 260$ ). 


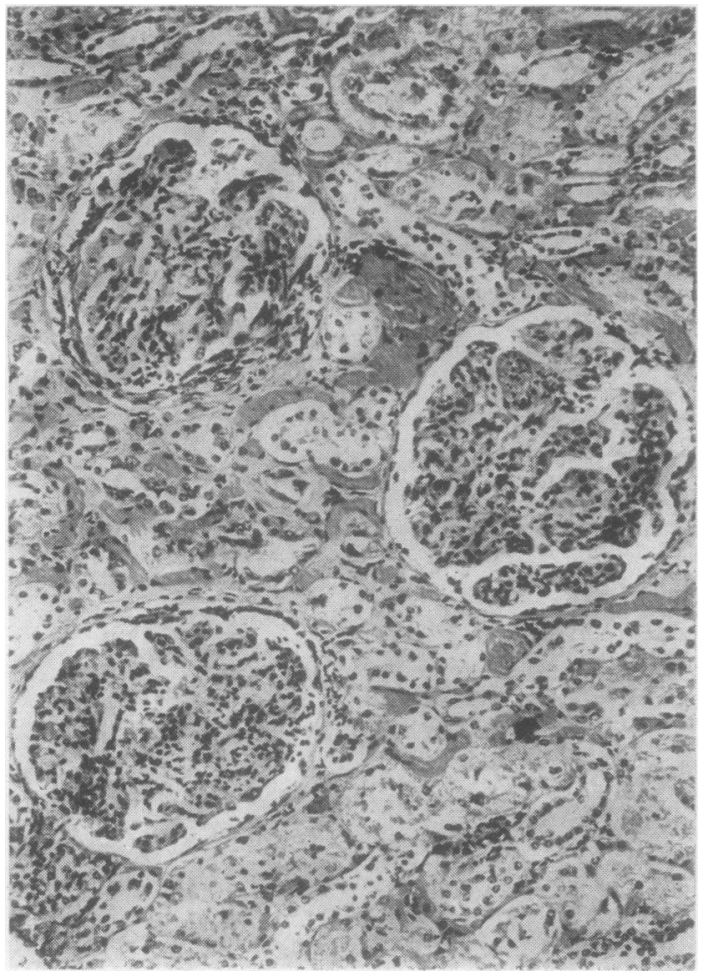

FIG. 6.-Case 2: swollen glomeruli with cellular infiltration (haematoxylin and eosin, $: 110$ ).

had felt unwell. He noticed that his urine was scanty and his sputum blood-stained. Though he had had a productive cough for many years, there had never been any blood present before. In June, 1956, he had had an illness characterized by headache, frequency of micturition, and polydipsia. Ankle oedema and hypertension were found by his doctor. Since then he had had increasing exertional dyspnoea.

In 1952 he had undergone nine months' sanatorium treatment for pulmonary tuberculosis, and a follow-up chest radiograph in April, 1956, showed some infiltration at the left apex and increasing hilar shadows.

On admission he was dyspnoeic at rest, cyanotic, and anaemic. His pulse rate was 100 per minute but regular. The blood pressure was $205 / 90 \mathrm{~mm}$. $\mathrm{Hg}$. Jugular venous pressure was not increased. The apex beat was impalpable and the heart sounds though distant were normal. There was conspicuous oedema of the ankles and sacrum. There were scattered rales and expiratory rhonchi at both bases. The liver and spleen were not felt and there was no lymphadenopathy. There was a right inguinal hernia. The prostate was small and nodular. The central nervous system was normal. An ophthalmologist reported gross uraemic changes in both fundi.

The haemoglobin was $8.8 \mathrm{~g}$. per $100 \mathrm{ml}$. and the red count 3,000,000 per c.mm., M.C.V. $90 \mathrm{c} \mu$ and
M.C.H.C. $32.6 \%$. The white count was 11,000 per c.mm. (73\% neutrophils, $11 \%$ monocytes, $15 \%$ lymphocytes). The urine contained a large amount of protein and a few red cells. No white cells were seen. Culture was negative. The sputum contained some pus cells and a mixed flora. Acid-fast bacilli were not found on smear nor were they isolated later on culture. The blood urea was $322 \mathrm{mg}$. per $100 \mathrm{ml}$. Total serum proteins were $5.9 \mathrm{~g}$. per $100 \mathrm{ml}$. and electrophoresis showed a very low albumin and a lowish $\alpha$-globulin fraction. Occult blood examinations and stool cultures were negative. An E.C.G. showed clockwise rotation. On chest radiography coarse bilateral pulmonary shadowing was seen extending outwards from the hila, suggesting pulmonary oedema. Emphysema was conspicuous and there was some old shadowing at the apex of the left upper lobe.

His course was steadily downhill and he became anuric. The blood urea rose to $354 \mathrm{mg}$. per $100 \mathrm{ml}$. two days before death. He died in renal failure on October 10, 1956.

\section{Post-MORTEM Findings (P56/406)}

The left pleural cavity contained $120 \mathrm{ml}$. of bloodstained fluid. There were fibrous adhesions over both the upper lobes and on the diaphragmatic surface of the right lung. The lower lobes were oedematous and congested and there was considerable deposition of pigment throughout the lung with some destruction of tissue. The pulmonary arteries showed moderate atheromatous change. There was a large old tuberculous cavity in the left upper lobe.

The kidneys were slightly enlarged (185 and 195 g.) and had pale mottled yellowish-red surfaces on which there were a few petechial haemorrhages. On section the cortices were opaque and creamy-yellow. The pattern was somewhat blurred and the cortico-medullary demarcation was obscured. The lower urinary tract was normal.

The left ventric'e of the heart was hypertrophied, but the myocardium and the coronary circulation were normal.

No abnormality was found in any other organ.

Microscopy.-There was massive intra-alveolar haemorrhage. Over large areas the alveoli contained red cells and many haemosiderin-laden macrophages. Early organization and fibrosis had occurred in places. One pulmonary artery had curious gaps in the media and the elastic lamina. There was, however, no inflammatory cell infiltration in or around the wall. The severest lesions were towards the hilum. The other vessels were normal.

The kidneys resembled those in Case 1. All the glomeruli were abnormal. Granulomatous transformation and varying degrees of fibrosis were the commonest lesions. A few tufts showed mild proliferative changes and occasionally masses of amorphous fibrinoid material partially replaced the glomeruli. A few giant cells were present. Epithelia crescent formation had occurred but to a less marked degree 
than in Case 1. Many tubules were dilated and contained protein.

CASE 4.-A 28-year-old stable boy was admitted to hospital on March 8, 1956, with haemoptysis and lassitude.

He had been well until three weeks before admission. He had then begun to have a daily haemoptysis of a dessertspoonful of blood-stained sputum in the morning. He had no cough during the rest of the day. One week before admission he noticed increasing lassitude and had taken to his bed. He felt giddy if he got up. His appetite was good and his weight steady. Apart from one attack of vomiting on the day of admission there were no other alimentary symptoms. Headaches had recently disturbed sleep. He had had no night sweats. Past history revealed only pneumonia in 1944.

On examination he was pale and ill. His temperature was $98.6^{\circ} \mathrm{F}$., pulse 100 per minute, and the blood pressure $160 / 65 \mathrm{~mm}$. Hg. The heart was normal except for a soft systolic apical murmur. The lungs were clear. There were no signs in the abdomen, the central nervous system, or the lymphatic systems. Hess's test was negative.

Investigations showed a haemoglobin of $5.4 \mathrm{~g}$. per $100 \mathrm{ml}$. The red count was $1,750,000$ per c.mm.; the indices M.C.V. 97 c $\mu$, M.C.H.C. $32 \%$, and reticulocytes $12 \%$. The white count was 9,800 per c.mm. and the differential count normal. The E.S.R. was $90 \mathrm{~mm}$. in one hour. The van den Bergh reaction was normal. The urine contained much protein, a large number of red cells and a few white cells and epithelial cells. The sputum was heavily blood-stained, but neither acid-fast bacilli nor other pathogens could be demonstrated. A chest radiograph showed coarse diffuse miliary mottling throughout both lung fields. Bleeding time, clotting time, and the platelets were normal. The prothrombin content was $70 \%$. The blood urea was $86 \mathrm{mg}$. per $100 \mathrm{ml}$.

He was treated with blood transfusion with no improvement. The sputum remained copious and blood-stained, and the haemoglobin continued to fall. His urinary output remained satisfactory. After a transfusion on March 16 he became dyspnoeic and many rales were heard throughout the chest. He died on March 17.

\section{POST-MORTEM FindingS}

The lungs were bulky, haemorrhagic, and oedematous. On cut section each lung had a coarse granularity due to tiny grey consolidated foci, many of which were coalescing. These projected from the dark red-brown background. Blood exuded from the main and branch bronchi.

The kidneys were hyperaemic and the cut surfaces bulged. The cortico-medullary junction was somewhat blurred. The lower urinary tract was normal.

The heart was normal and no other abnormalities were found.

MICROSCOPY.-There were very numerous and extensive intra-alveolar haemorrhages. In many areas there was also fibrin in the alveoli, and much of this was undergoing organization. Throughout the affected areas there were large numbers of haemosiderin-laden macrophages. The distribution of the lesions in relation to the bronchioles was hard to define, but both focal and diffuse lesions were present. The pulmonary arteries were normal.

The glomeruli showed a little endothelial proliferation with polymorphonuclear infiltration. Some fibrinoid necrosis was present within certain tufts. Epithelial crescents had formed and the capsular spaces were filled with red blood corpuscles. Many afferent arterioles were hyalinized.

\section{Discussion}

Few cases of this disease have been reported. Heptinstall and Salmon (1959) reviewed the literature, finding five cases, and added three of their own. The five cases reviewed all occurred in children. The lung changes were typical, but in only one was the nature of the renal lesions clear. This was a case of polyarteritis nodosa. Similarly Case 1 of their own series had the typical widespread lesions, but the renal changes in the other two were more complex. These they consider to be a mixture of glomerulonephritis and polyarteritis. Stanton and Tange (1958) reported a series of nine cases and, incidentally, brought to light Goodpasture's description of the first case. This case was described under " pulmonary lesions in influenza." At necropsy arterial lesions were found in the kidneys, spleen, and intestines, which suggests a diagnosis of polyarteritis. In their own cases Stanton and Tange considered the glomerular lesions to be compatible with polyarteritis but were reluctant to accept such a diagnosis in the absence of widespread arterial damage. They found only one artery damaged in a kidney in their whole series. Parkin, Rusted, Burchell, and Edwards (1955) in seven cases combined glomerular lesions, suggestive of polyarteritis but without renal arterial damage, with necrotizing alveolitis as the cause of the haemosiderosis in the lungs. This is the only group in which the cause of the haemosiderosis is evident.

Our cases and those in the literature indicate that most patients with pulmonary haemosiderosis and severe renal lesions follow a quite well-defined clinical course. The presenting symptoms are usually pulmonary, often a haemoptysis and slowly progressive dyspnoea. A profound progressive and refractory anaemia develops and renal involvement then becomes apparent. The onset of renal manifestations varies from immediate to a period of months. There is some variation in this pattern. The longest surviving cases appear at first to be entirely pulmonary and radiologically 
may have miliary mottling in the lungs. The renal lesion is not detected in the later stages of the disease. The shorter surviving group may present with obvious renal involvement and coexisting pulmonary symptoms. Renal failure is usually the cause of death, and all cases so far reported have been fatal.

Two views have been expressed to explain the pathogenesis of the haemosiderosis. Since both focal and diffuse lesions are present in each case, it is important to decide whether focal haemorrhages or diffuse leakage of blood is responsible for the changes seen. Lendrum et al. (1950) suggested that focal haemorrhage was responsible for the haemosiderosis seen in mitral stenosis, as the iron-containing cells were aggregated into welldefined areas. Gough (1953) suggested, on the analogy of inhaled carbon particles which are diffusely distributed at first and then become focal, that the haemorrhage producing the foci of haemosiderin could also be diffuse. Parker (1958) examined cases of mitral stenosis with Gough's viewpoint in mind and came to the conclusion that haemorrhage producing the foci was diffuse. This view is more compatible with the suggestion of Parkin et al. (1955) that the basis of the disease is hypersensitivity. Diffuse leakage from the alveolar capillaries could be caused by this with or without the gross changes found in their cases. In the absence of known pulmonary hypertension such a mechanism seems likely, though there is no other evidence as yet to substantiate such a hypothesis.

The glomerular lesions in three of our cases $(1,3$, and 4) resembled the lesions described by Davson, Ball, and Platt (1948) as characteristic of polyarteritis nodosa. Case 2 was not typical, but it could represent an earlier stage of the characteristic lesion. None of the lesions could be diagnosed as acute glomerulonephritis. We therefore agree with the conclusion of Stanton and Tange (1958) that the lesions in this disease are similar in certain respects to polyarteritis nodosa. Can this form of pulmonary haemosiderosis then be regarded as a kind of polyarteritis nodosa? For classically polyarteritis nodosa is a disease of small and medium-sized arteries of wide distribution, and it is doubtful whether one can classify a disease as such if the arterial lesions are not widespread. Lesions typical of polyarteritis can be found confined to a few or one organ in diseases which are manifestly not polyarteritis nodoš, for example, the vascular lesions found in lungs in mitral stenosis (Parker, 1958). In our present series of cases it is to be noted that the acute arterial lesions with necrosis and inflammatory cell infiltration are confined to kidneys and lungs. This distribution is not wide enough for poly- 흠 arteritis nodosa, for Nuzum and Nuzum (1954), in $\frac{\bar{c}}{\frac{\rho}{\sigma}}$ a survey of 175 cases of polyarteritis nodosa, state $\mathbb{\otimes}$ that the arterial lesions are widespread and involving kidney, heart, and brain in $66 \%$ to $85 \%$ \% of cases, and only in acute cases may the lesions $\vec{\circ}$ be restricted to one or two organs. Acute arterial $\overrightarrow{\vec{\omega}}$ lesions were sparse in the cases in the literature. $\stackrel{\omega}{\omega}$ In the first case described by Goodpasture the $\vec{x}$ spleen was involved, as also in the case from the ${ }^{x}$ Hammersmith Hospital (Clinicopathological Con- $\vec{\sigma}$ ference, 1954). The splenic arteries were involved $\vec{i}$ in four of the seven patients described by Parkin $N$ et al. (1955) and the lung in one. Of the nine $\frac{\text { O }}{2}$ cases of Stanton and Tange, only one had an artery $\vec{r}$ in the kidney involved and in none were the lung vessels damaged. Stanton and Tange do not consider their cases to be polyarteritis nodosa on $\underset{\supset}{\supset}$ the basis of, first, the lack of arterial lesions and, $\mathscr{\odot}$ secondly, on the difference in clinical and patho- logical patterns from those cases of polyarteritis with pulmonary involvement described by Rose and Spencer (1957). They suggest that the syndrome should be called Goodpasture's syndrome until it is further clarified. With this $\frac{2}{\square}$ we concur.

However, we are a little more impressed by the arterial lesion in our cases and from the literature, $\vec{\partial}$ and, while we agree with Stanton and Tange that the cases have different clinical and pathological patterns from cases of polyarteritis nodosa with $\bar{\sigma}$ pulmonary involvement, nevertheless we cannot entirely exclude the hypothesis that they are a $\dot{\sigma}$ distinct further pulmonary type of polyarteritis 3 . nodosa.

\section{SUMmaRY}

Clinical and pathological features of four cases 윽 of pulmonary haemosiderosis with renal lesions $?$ (Goodpasture's syndrome) are presented. From these a fairly distinct clinical picture emerges. N Most cases present with haemoptysis and renal $N$ failure follows, either almost at once or up to a year after.

The renal lesions are unlike those of glomerulonephritis, but bear some resemblance to certain lesions found in polyarteritis nodosa.

The aetiology of the disease is discussed with $\stackrel{?}{?}$ particular reference to its relationship to poly- $\frac{T}{T}$ arteritis nodosa; it is considered probably not to $\frac{\vec{D}}{\mathbb{D}}$ be a form of polyarteritis nodosa.

In the absence of a satisfactory aetiological $\stackrel{\square}{\circledR}$ group into which the disease could be classified. it is suggested that it be referred to as "Goodpasture's syndrome." 


\section{ADDENDUM}

Since this communication was submitted, Rusby and Wilson (1960) have published a paper on this subject discussing five cases similar to our own. They consider the condition analogous to the Henoch-Schönlein syndrome.

We should like to thank Dr. L. Cole, Dr. L. C. Martin, Dr. A. P. Dick, and Dr. C. P. Hay for access to the case records and for permission to publish details of their cases. We are indebted to Dr. J. H. Dean for the post-mortem report of Case 4. Mr. R. Patman kindly took the photomicrographs.

\section{REFERENCES}

Ceelen, W. (1931). In Handbuch der speziellen pathologischen Anatomie und Histologie, ed. F. Henke and O. Lubarsch, Band 3 , Teil 3, p. 20. Springer, Berlin.

Clinicopathological Conference No. 21 (1954). Postgrad. med. J., 30,35 .

Davson, J., Ball, J., and Platt, R. (1948). Quart. J. Med., n.s. 17, 175.

Goodpasture, E. W. (1919). Amer. J. med. Sci., 158, 863.

Gough, J. (1953). In Recent Advances in Pathology, 6th ed., p. 209, ed. G. Hadfield. Churchill, London.

Hamer, N. A. J. (1955). Brit. med. J., 1, 1008.

Heptinstall, R. H., and Salmon, M. V. (1959). J. clin. Path., 12, 272.

Lendrum, A. C., Scott, L. D. W., and Park, S. D. S. (1950). Quart. J. Med. n.s. 19, 249 .

Lloyd Rusby, N., and Wilson, Clifford (1960). Ibid., n.s. 29, 501.

Nuzum, J. W. Jr., and Nuzum, J. W. Sr. (1954). A.M.A. Arch. intern. Med., 94, 942.

Parker, R. A. (1958). Stanf. med. Bull., 16, 87.

Parkin, T. W., Rusted, I. E., Burchell, H. B., and Edwards, J. E. (1955). Amer. J. Med., 18, 220.

Rose, G. A., and Spencer, H. (1957). Quart. J. Med., n.s. $26,43$.

Stanton, M. C., and Tange, J. D. (1958). Aust. Ann. Med., 7, 132. 